\title{
PRODUÇÃO DE SULFATO FERROSO MONO HIDRATADO A PARTIR DE CAREPA
}

\author{
L. M. FURMANSKI ${ }^{1,2}$, K. M. BENEDET ${ }^{2}$, C. M. MACHADO ${ }^{2}$, A. B. C. ARNT ${ }^{3}$, \\ M. R. da ROCHA ${ }^{1,3}$, M. PETERSON ${ }^{1,2}$
}

${ }^{1}$ Universidade do Extremo Sul Catarinense, Programa de Pós-Graduação em Ciência e Engenharia de Materiais, Grupo de Pesquisa VALORA (Desenvolvimento de materiais a partir de resíduos)

${ }^{2}$ Universidade do Extremo Sul Catarinense, Departamento de Engenharia Química, Grupo de Pesquisa LabRePI (Laboratório de Reatores e Processos Industriais)

${ }^{3}$ Universidade do Extremo Sul Catarinense, Departamento de Engenharia de Materiais E-mail para contato: lumilak@hotmail.com

\begin{abstract}
RESUMO - O resíduo industrial utilizado para a produção de sulfato ferroso é a carepa oriunda do processo de laminação a quente de aço. A carepa é constituída basicamente por ferro na forma de óxidos e, por isso, pode ser utilizada como precursora de produto químico a base de ferro, como o sulfato ferroso. A produção deste material se dá por meio de uma rota química, com preparos de ataque químico com $\mathrm{H}_{2} \mathrm{SO}_{4}$, aquecimento, filtragem, concentração, resfriamento e cristalização. Inicialmente, o resíduo foi caracterizado por DRX e FRX para determinação das fases cristalinas e composição química respectivamente. E, após o processo químico, realizou-se ensaio de caracterização do material obtido por DRX, identificando o sulfato ferroso mono hidratado como única fase presente e confirmando a aplicação do resíduo industrial denominado carepa como fonte para produção do produto químico $\mathrm{FeSO}_{4}$.
\end{abstract}

\section{INTRODUÇÃO}

A indústria siderúrgica gera elevada quantidade de resíduos sólidos, de diferentes composições, durante o processo de fabricação do aço, incluindo a carepa gerada durante os processos de lingotamento e laminação (Martins, 2006; Cunha et al., 2006b). O processo de laminação de aço é considerado uma atividade do setor metalúrgico, incluso na siderurgia.

Durante o aquecimento do tarugo de aço, antes da etapa de passagem pelos cilindros do laminador, a camada superior do mesmo pode ser oxidada quando submetido ao gradiente térmico ou por meio de uma reação com o meio externo durante as etapas de conformação e resfriamento, ambas do processo de laminação, formando a carepa (Leite, 2008; Ahmed et al., 2009; Castro et al., 2006; Cunha et al., 2006b).

A carepa é constituída basicamente por óxidos de ferro na forma de $\mathrm{Fe}^{+2}(\mathrm{FeO}-$ wustita), $\mathrm{Fe}^{+3}\left(\mathrm{Fe}_{2} \mathrm{O}_{3}\right.$ - hematita) e $\mathrm{Fe}_{3} \mathrm{O}_{4}$ - magnetita (Martins, 2006; Cunha et al., 2006a; Pannoni, 2007). A presença de óxidos, normalmente, é superior a 90\% (Cunha et al., 2006a; Della, 2005). Além do elevado teor de ferro na forma de óxidos, elementos como manganês, cromo, níquel e silício podem ficar incorporados (Santos et al., 2000 apud Della, 2005). 
Contudo, devido às características que este resíduo apresenta, os quais são citados por Ahmed et al., 2009, como: elevado teor de ferro e baixo percentual de impurezas, a carepa pode ser utilizada para produção de produtos químicos a base de ferro, como é o caso do sulfato ferroso que é o objetivo deste trabalho, assim como outros materiais.

\subsection{Produção de sulfato ferroso a partir de resíduos}

$\mathrm{O}$ sulfato ferroso $\left(\mathrm{FeSO}_{4}\right)$ é um produto químico que é encontrado naturalmente nas formas hidratadas, sendo que o grau de hidratação pode ser de 1, 4, 5 ou 7 moléculas de água (mono, tetra, penta ou hepta respectivamente).

Segundo Peterson (2008), o sulfato ferroso pode ser produzido comercialmente a partir do processo de produção do dióxido de titânio; o ataque por ácido sulfúrico à rocha de ilmenita $\left(\mathrm{FeTiO}_{2}\right)$ produz um liquor concentrado em sulfato ferroso que, após resfriamento, cristaliza na forma de sulfato ferroso hepta hidratado.

Algumas aplicações deste produto são: medicina (Torres et al., 2004), alimentos (Cocato et al., 2007), rações animais (Bertechini et al., 2000), tratamento de efluentes (Campos e Brito, 2014), entre outras. As pesquisas que trabalharam com o intuito de produzir sulfato ferroso foram a de Peterson (2008) com o uso da pirita contida nos rejeitos da mineração de carvão no sul catarinense, o de Cardoso (2012) com a utilização de resíduos da mineração de ferro e o de Vigânico (2009) que trabalhou com rejeitos de carvão.

\section{PROCEDIMENTO EXPERIMENTAL}

A pesquisa consiste na aplicação da carepa, resíduo industrial, em um processo de reciclagem por rota química para produção de um produto químico de valor agregado, o sulfato ferroso mono hidratado. O processo de obtenção deste material se deu por meio de uma rota química baseada na tese de Peterson (2008), recebendo algumas adaptações.

Uma amostra simples de resíduo foi coletada seguindo os procedimentos de amostragem especificados na ABNT NBR 10.007/2004. A caracterização da carepa foi realizada por meio de ensaios de difração de raios $\mathrm{X}$ (DRX) para determinação das fases cristalinas presentes e análise da composição química por fluorescência de raios X (FRX).

Inicialmente, a carepa foi seca em estufa em torno de $40{ }^{\circ} \mathrm{C}$. Após a secagem, a mesma foi submetida à etapa de moagem em moinho excêntrico com esferas de alta alumina (Servitech/CT-242), por cerca de $30 \mathrm{~min}$, visando coletar a carepa passante na peneira de malha de 200 mesh para a realização dos experimentos.

Após o preparo da amostra, a carepa foi imersa em água e atacada quimicamente com ácido sulfúrico $\left(\mathrm{H}_{2} \mathrm{SO}_{4}\right)$. Esta solução passou por aquecimento a temperatura e tempo predeterminados a fim de ocorrer a reação desejada, evaporando-se a água presente e formando uma solução de sulfato ferroso.

A solução foi filtrada em filtros de papel com o auxílio de bomba a vácuo com o intuito de remover a massa sólida residual. Feito isso, realizou-se a etapa de concentração, que 
compreendeu em um novo aquecimento para remoção da água introduzida na filtragem, obtendo-se uma solução mais concentrada e densa, com cristais de sulfato se formando.

Feito isso, o precipitado foi enviado ao resfriamento em congelador para auxiliar na cristalização do material e, por fim, encaminhado à estufa para secagem. O material obtido foi enviado para realização do ensaio de caracterização por DRX.

Vale comentar que os ensaios de DRX foram realizados em difratômetro de raios $\mathrm{X}$ (Shimadzu/XRD-6000), com varredura entre 10 a $80^{\circ}$, velocidade de $2 \% / \mathrm{min}$, voltagem de 30 $\mathrm{kV}$, corrente de $30 \mathrm{~mA}$ e comprimento de onda $\mathrm{Cu} \mathrm{K}-\alpha 1 \lambda=1,5406 \AA$, enquanto o FRX foi feito em espectrômetro de FRX (Axios Max Panalytical).

\section{RESULTADOS E DISCUSSÃO}

A amostra de resíduo foi coletada na metalúrgica logo no momento em que o tarugo de aço saiu do forno e entrou em contato com o ambiente externo. Neste momento, a carepa foi gerada, removida e disposta em container (Figura 1). A carepa consiste em partículas na forma de placas irregulares, com tamanhos variados, de cor cinza metálico (Figura 1B).

Figura 1 - (A) Remoção da carepa formada sobre o tarugo, e (B) local de coleta da amostra.

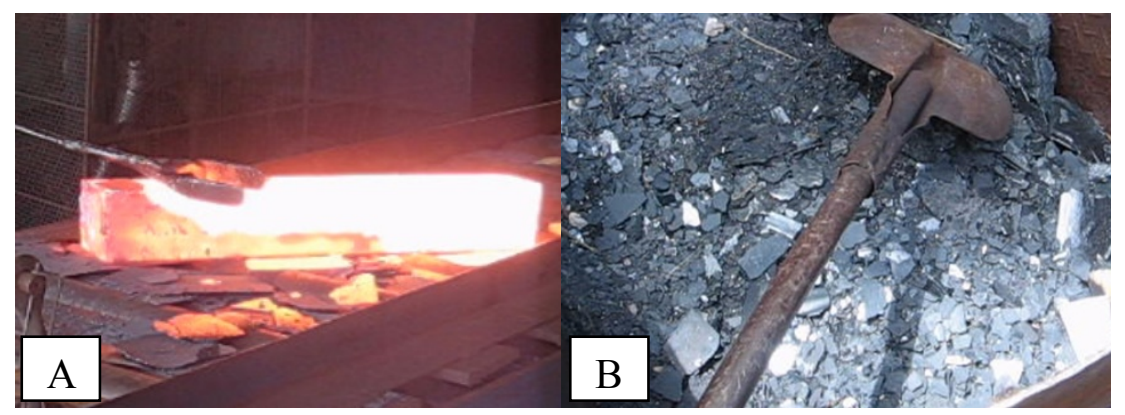

Com relação à determinação das fases cristalinas presentes no resíduo, a análise por DRX apresentou wustita como fase majoritária, seguida por magnetita e hematita (Figura 2), componentes característicos da carepa.

Figura $2-$ DRX da carepa.

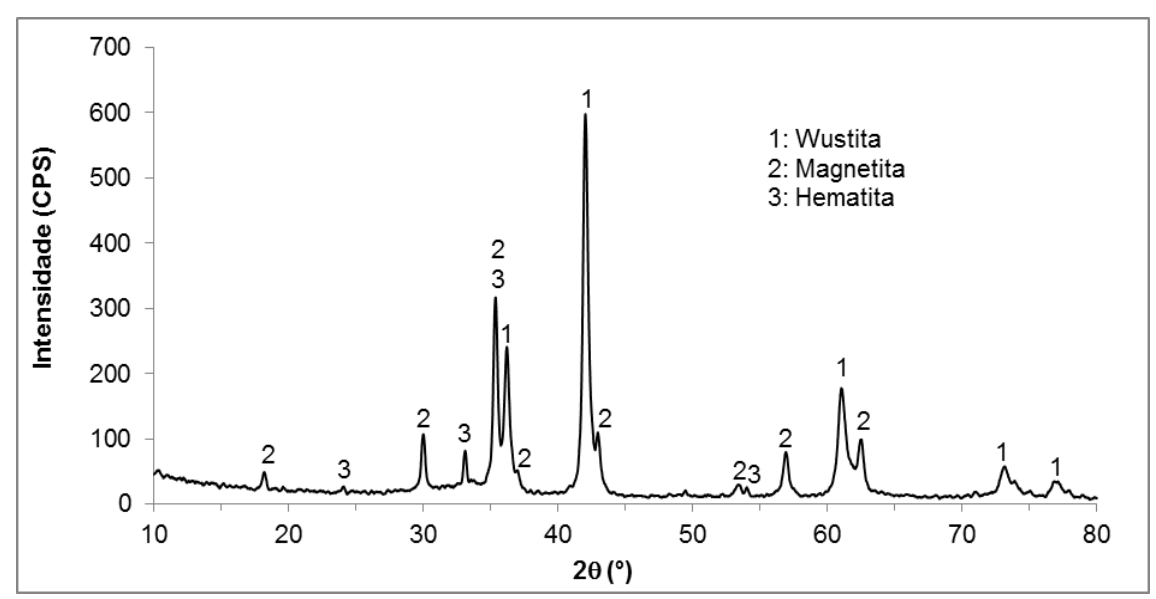


A presença de hematita como fase minoritária é considerado um fator positivo, visto que este óxido é mais estável e, consequentemente, mais difícil de ser atacado pelo ácido.

Com o intuito principal de determinar a quantidade de óxido de ferro presente na carepa, caracterizada por wustita, magnetita e hematita de acordo com a análise por DRX apresentada acima, foi realizada análise química por FRX. Os resultados deste ensaio encontram-se expostos na Tabela 1.

Tabela 1 - Análise química por FRX da carepa

\begin{tabular}{cc}
\hline Elemento & Teor \\
\hline $\mathrm{Al}_{2} \mathrm{O}_{3}$ & 0,75 \\
$\mathrm{Fe}_{2} \mathrm{O}_{3}$ & 97,90 \\
$\mathrm{MnO}$ & 0,69 \\
$\mathrm{SiO}_{2}$ & 0,73 \\
$\mathrm{Cr}_{2} \mathrm{O}_{3}$ & 0,09 \\
Perda ao fogo & N. D. \\
\hline
\end{tabular}

Analisando estes resultados, pode-se constatar que a presença de óxido de ferro é de fato bastante elevada, neste caso, alcançando um percentual de quase $98 \%$. Com relação aos óxidos de manganês e silício, os valores são relevantes em função da presença dos elementos Mn e Si na composição do tarugo de aço SAE 1020, o qual teve sua superfície oxidada, gerando a amostra de carepa utilizada neste estudo. Houve interferência externa na presença de óxidos de alumínio devido à provável contaminação por alumina no momento da moagem. O percentual de óxidos de cromo identificado provavelmente refere-se a impurezas presentes no tarugo de aço 1020.

Após a caracterização do resíduo, os ensaios de produção de sulfato ferroso com a amostra simples foram realizados. E, com o material obtido, caracterizações foram feitas para comprovar a formação de sulfato ferroso e identificar seu nível de hidratação.

As análises por DRX identificaram a presença de szomolnokita (sulfato ferroso mono hidratado - $\mathrm{FeSO}_{4} \cdot \mathrm{H}_{2} \mathrm{O}$ ) como única fase cristalina presente, conforme Figura 3.

Figura 3 - DRX do material obtido (sulfato ferroso mono hidratado).

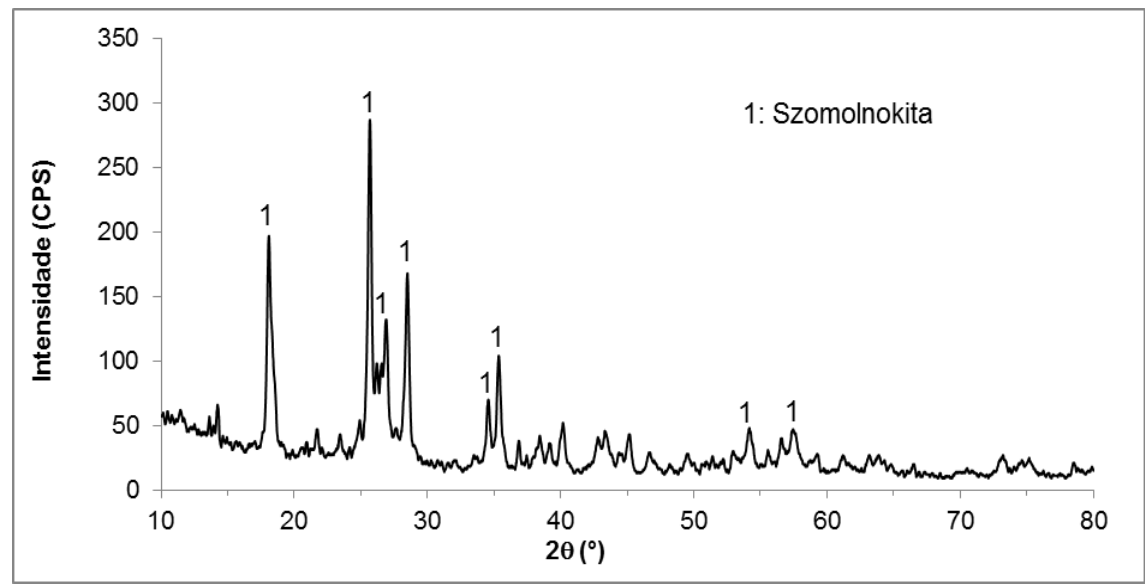


Mesmo após a produção do sulfato ferroso mono hidratado por meio de um rota química testada, haverá otimizações do processo de obtenção do material e, até mesmo, tentativas de obtenção de um sulfato ferroso com maior grau de hidratação.

\section{CONCLUSÃO}

O projeto em questão permitiu comprovar que um resíduo sólido industrial pode ser aplicado como fonte no desenvolvimento de materiais. Neste caso, desenvolveu-se um processo de reciclagem para obtenção de um produto químico de valor agregado, contribuindo, inclusive, com a recente legislação brasileira que institui a Política Nacional de Resíduos Sólidos e prioriza o gerenciamento dado aos resíduos pela reciclagem ao invés da disposição final, que normalmente ocorre.

A pesquisa atingiu o objetivo principal que consistia na produção do sulfato ferroso partindo-se da carepa, revelando um eficiente método de obtenção aqui proposto. A rota química utilizada para produção de sulfato ferroso mono hidratado também serve como ponto de partida para o desenvolvimento de otimizações para produção deste produto em escala industrial.

\section{REFERÊNCIAS}

AHMED, Y. M. Z., HESSIEN, M. M., RASHAD, M. M., IBRAHIM, I. A. Nano-crystalline copper ferrites from secondary iron oxide (mill scale). Journal of Magnetism and Magnetic Materials, v. 321. p. 181-187, 2009.

ASSOCIAÇÃO BRASILEIRA DE NORMAS TÉCNICAS - ABNT. NBR 10.007: amostragem de resíduos sólidos. Rio de Janeiro: 2004. 25 p.

BERTECHINI, A.G.; FASSANI, E.G.; FIALHO, E.T. Suplementação de Ferro para Poedeiras Comerciais do Segundo Ciclo de Produção. Revista Brasileira de Ciência Avícola, v. 2, n. 3, p. 267-272, set. 2000.

BRASIL. Lei $\mathrm{n}^{\circ}$ 12.305, de 02 de agosto de 2010. Institui a Política Nacional de Resíduos Sólidos; altera a Lei $\mathrm{n}^{\circ} 9.605$, de 12/02/1998; e dá outras providências. D.O.U., Brasília, DF, 03 ago. 2010. Disponível em: http://www.planalto.gov.br/ccivil_03/_ato20072010/2010/lei/112305.htm. Acesso em: 26 out. 2013.

CAMPOS, V. M.; BRITO, N. N. de. Tratamento de efluente têxtil utilizando coagulação/floculação e Fenton. Revista de Química Industrial, v. 743, p. 11-17, 2014.

CARDOSO, K. A. Produção de sulfato ferroso a partir do resíduo proveniente da mineração de ferro. 2012. 81 f. Dissertação (Pós-Graduação em Engenharia Química).

Universidade Federal de Santa Catarina, Florianópolis.

CASTRO, G. M.; ROSSI, E. H.; CASTRO, L. F. A. de; SANTOS, D. B. Caracterização da carepa em aço inoxidável ferrítico ABNT 430. Tecnologia em Metalurgia e Materiais, São Paulo, v. 3. n. 1, p. 40-44, 2006. 
COCATO M.L; RÉ M.I; NETO M.A.T; CHIEBAO E.P; COLLI. C. Avaliação por Métodos in Vitro e in Vivo da Biodisponibilidade de Sulfato Ferroso Micro encapsulado. Revista de Nutrição. v. 20, n. 3, p. 239-247, jun. 2007.

CUNHA, A. F. da; ARAÚJO FILHO, G. de; MARTINS JÚNIOR, A.; GOMES, O. C. B.; ASSIS, P. S. Aspectos técnicos da utilização da carepa gerada em processos siderúrgicos e tratada por desagregação ultra-sônica. Tecnologia em Metalurgia e Materiais, São Paulo, v. 3. n. 2, p. 1-5, 2006a.

CUNHA, A. F.; MOL, M. P. G.; MARTINS, M. E; ASSIS, P. S. Caracterização, beneficiamento e reciclagem de carepas geradas em processos siderúrgicos. Metalurgia \& Materiais, v. 59, n. 1, p. 111-116, 2006b.

DELLA, V. P. Síntese e caracterização do pigmento cerâmico de hematita, obtida a partir de carepa de aço, encapsulada em sílica amorfa obtida a partir de casca de arroz. 2005. 145 f. Tese (Pós-Graduação em Ciência e Engenharia de Materiais). Universidade Federal de Santa Catarina, Florianópolis.

LEITE, W. F. Dissolução de óxidos formados a altas temperaturas nos aços elétricos variando-se a temperatura e concentração da solução ácida na decapagem. $2008.60 \mathrm{f}$. Dissertação (Pós-Graduação em Engenharia Metalúrgica e de Minas). Universidade Federal de Minas Gerais, Belo Horizonte.

MARTINS, F. M. Caracterização química e mineralógica de resíduos sólidos industriais minerais do estado do Paraná. 2006. 140 f. Dissertação (Pós-Graduação em Química). Universidade Federal do Paraná, Curitiba.

PANNONI, F. D. Coletânea do uso do aço: princípios da proteção de estruturas metálicas em situação de corrosão e incêndio. GERDAU: 2007. 4. ed. 90 p.

PETERSON, M. Produção de sulfato ferroso a partir da pirita: desenvolvimento sustentável. 2008. 127 f. Tese (Pós-Graduação em Engenharia Química). Universidade Federal de Santa Catarina, Florianópolis.

TORRES, M. A. A.; SATO, K.; JULIANO, Y.; QUEIROZ, S. S.; Terapêuticas com doses profiláticas de sulfato ferroso como medida de intervenção no combate à carência de ferro em crianças atendidas em unidades básicas de saúde. Revista de Saúde Pública, v. 28 , n. 6, p. 410-415, 2004

VIGÂNICO, E. M. Produção de sulfato ferroso a partir de rejeitos de carvão. 2009. $70 \mathrm{f}$. Dissertação (Pós-Graduação em Engenharia de Minas, Metalúrgica e de Materiais). Universidade Federal do Rio Grande do Sul, Porto Alegre.

\section{AGRADECIMENTOS}

Ao PROSUP/CAPES e ao PIBIC/CNPq/UNESC, pelos recursos disponibilizados. 